\title{
Increased intake of vegetable oil rich in $n$ - 6 PUFA enhances allergic symptoms and prevents oral tolerance induction in whey-allergic mice
}

\author{
Lieke W. J. van den Elsen ${ }^{1}$, Betty C. A. M. van Esch $^{1,2}$, Gemma M. Dingjan ${ }^{1,2}$, Gerard A. Hofman ${ }^{1}$, \\ Johan Garssen ${ }^{1,2}$ and Linette E. M. Willemsen ${ }^{1 *}$ \\ ${ }^{1}$ Division of Pharmacology, Utrecht Institute for Pharmaceutical Sciences, Utrecht University, Universiteitsweg 99, \\ 3584 CG Utrecht, The Netherlands \\ ${ }^{2}$ Nutricia Research, Centre for Specialised Nutrition, Uppsalalaan 12, 3584 CT Utrecht, The Netherlands
}

(Submitted 11 December 2014 - Final revision received 10 April 2015 - Accepted 5 May 2015 - First published online 16 July 2015)

\section{Abstract}

Increased intake of vegetable oils rich in $n-6$ PUFA, including soyabean oil, has been associated with an increase in allergic disease. The present study aimed to determine the effect of an increasing dose of dietary vegetable oil on allergic outcomes in mice. To study this, mice received a $7 v .10 \%$ soyabean oil diet before and during oral sensitisation with whey or whey hyperimmune serum transfer. Another group of mice received partial whey hydrolysate (pWH) while being fed the diets before oral sensitisation. The acute allergic skin response, serum Ig level, mouse mast cell protease-1 (mMCP-1) concentration and/or splenic T-cell percentages were determined upon whey challenge. When the diets were provided before and during oral sensitisation, the acute allergic skin response was increased in mice fed the $10 \%$ soyabean oil diet compared with the $7 \%$ soyabean oil diet. Whey IgE and IgG1 levels remained unaltered, whereas mMCP-1 levels increased in mice fed the $10 \%$ soyabean oil diet. Furthermore, allergic symptoms were increased in naive mice fed the $10 \%$ soyabean oil diet and sensitised with whey hyperimmune serum. In addition to enhancing the mast cell response, the $10 \%$ soyabean oil diet increased the percentage of activated Th1 and Th2 cells as well as increased the ratios of Th2:regulatory T cells and Th2:Th1 when compared with the $7 \%$ soyabean oil diet. Oral tolerance induction by pWH was abrogated in mice fed the $10 \%$ soyabean oil diet compared with those fed the $7 \%$ soyabean oil diet during pretreatment with pWH. In conclusion, increased intake of soyabean oil rich in $n$-6 PUFA suppresses tolerance induction by pWH and enhances the severity of the allergic effector response in whey-allergic mice. Dietary vegetable oils rich in $n$ - 6 PUFA may enhance the susceptibility to develop or sustain food allergy.

Key words: $n$-6 PUFA: Linoleic acid: Vegetable oils: Cows' milk allergy: Allergic skin response: Oral tolerance: T cells

The last decades have seen a dramatic increase in total PUFA intake in the Western society. This is mainly due to the decreased use of butter and lard and the increased intake of n-6 PUFA-rich dietary vegetable oils such as soyabean, maize and sunflower oil, and products such as margarines, which are especially rich in linoleic acid (LA; $18: 2 n-6)^{(1-3)}$. LA is an essential fatty acid, found in plants only, and a precursor of arachidonic acid (AA; $20: 4 n-6)^{(4)}$. Usually, $n-6$ PUFA are considered to be pro-inflammatory because of the range of inflammatory eicosanoids (e.g. PG) to which AA is metabolised by cyclo-oxygenases and lipoxygenases ${ }^{(5)}$. A diet rich in $n-6$ PUFA has been hypothesised to influence the development of allergic sensitisation as AA-derived eicosanoid $\mathrm{PGE}_{2}$ promotes the production of $\operatorname{IgE}^{(6)}$. Furthermore, fatty acids including $n-6$ PUFA can affect signal transduction pathways by binding to transmembrane and/or intracellular receptors or altering other signalling molecules ${ }^{(7)}$. For these reasons, the use of excessive amounts of $n$ - 6 PUFA may be linked to the increased incidence of allergic disease in Western countries, affecting $15-30 \%$ of the population ${ }^{(8)}$. Indeed, margarine intake (as a substitute for $n-6$ PUFA intake, as it contains ten to thirty times more LA than butter) has been associated with the increased incidence of allergic disease $^{(9-11)}$. Also, differences in the prevalence of asthma and allergic rhinitis and IgE levels are in accordance with differences in butter and margarine consumption in the former East and West Germany ${ }^{(12)}$. One of the first outcomes of atopic disease in infancy is cows' milk allergy, occurring in $0 \cdot 3-3.5 \%$ of young infants. The impaired development of tolerance or the breakdown of existing tolerance to milk proteins, including whey, can result in allergic conditions such as eczema, diarrhoea, respiratory problems or even systemic

Abbreviations: AA, arachidonic acid; LA, linoleic acid; mMCP-1, mouse mast cell protease-1; OT, oral tolerance; pWH, partial whey hydrolysate; Treg, regulatory T cells.

*Corresponding author: L. E. M. Willemsen, email 1.e.m.willemsen@uu.nl 
anaphylaxis $^{(13,14)}$. Regulatory T cells (Treg) are known to support oral tolerance (OT) induction ${ }^{(15)}$. Children with cows' milk allergy are also predisposed to develop other food or inhalant allergies, know as the allergic march ${ }^{(16)}$. Therefore, novel approaches to prevent or treat food allergies are of interest. So far, it is unknown whether $n$-6 PUFA-rich dietary vegetable oils, such as soyabean oil, may influence the risk of developing cows' milk allergy. The aim of the present study was to determine the effect of $7 v .10 \%$ dietary soyabean oil on allergic sensitisation and symptoms evoked by whey protein, and OT induction by partial whey hydrolysate (pWH) in a murine model of orally induced cows' milk allergy. This could indicate whether increased dietary n-6 PUFA intake increases the susceptibility to develop food allergy, which may open new venues for intervention. Potentially dietary interventions can be beneficial in the prevention of (food) allergy and related symptoms.

\section{Materials and methods}

\section{Animals}

Animal use in the present study was in accordance with the guidelines of the Animal Ethics Committee (AEC) of Utrecht University (AEC 2009.III.08.079). Specific pathogen-free female $\mathrm{C} 3 \mathrm{H} / \mathrm{HeOuJ}$ mice ( $n$ 6-8 per group; Charles River Laboratories), aged 3 weeks old, were fed a cows' milk proteinfree AIN-93G diet (containing 7\% soyabean oil) ${ }^{(17)}$ or a $10 \%$ soyabean oil diet (Research Diet Services). The fat percentage of AIN-93G was adapted by the exchange of soyabean oil with maize starch, as described previously ${ }^{(18)}$. Soyabean oil contained $59 \cdot 1 \%$ PUFA, of which $53 \cdot 1 \%$ was LA ( $n$-6 PUFA), 5.6\% $\alpha$-linolenic acid ( $n$-3 PUFA), $24.9 \%$ MUFA (oleic acid) and 15.1\% SFA (palmitic acid and stearic acid). The diets were stored at $-20^{\circ} \mathrm{C}$ until analysis.

\section{Oral sensitisation and challenge of mice}

Mice were fed the 7 or $10 \%$ soyabean oil diet, starting 2 weeks before the first sensitisation and continued during the whole sensitisation period until killing (Fig. 1(a)). Mice were sensitised intragastrically using a blunt needle with $20 \mathrm{mg}$ whey (DMV International) in $0.5 \mathrm{ml} \mathrm{PBS}$, with $10 \mu \mathrm{g}$ cholera toxin (CT; Quadratech Diagnostics) used as an adjuvant (DMV International and List Biological Laboratories, Inc.), while sham mice received cholera toxin $(10 \mu \mathrm{g} / 0.5 \mathrm{ml} \mathrm{PBS})$. Mice were orally sensitised once per week for five consecutive weeks, as described previously by Schouten et al. ${ }^{(19)}$. At 1 week after the last sensitisation, mice were challenged intradermally to determine the acute allergic skin response, anaphylactic shock and body temperature. On the same day, mice were challenged intragastrically with $50 \mathrm{mg}$ whey in $0.5 \mathrm{ml}$ PBS. At $18 \mathrm{~h}$ after oral challenge, blood samples were collected and centrifuged at $14000 \boldsymbol{g}$ for $15 \mathrm{~min}$. Serum was stored at $-70^{\circ} \mathrm{C}$ until analysis. Mice were killed by cervical dislocation, and the spleen was obtained for flow cytometry.
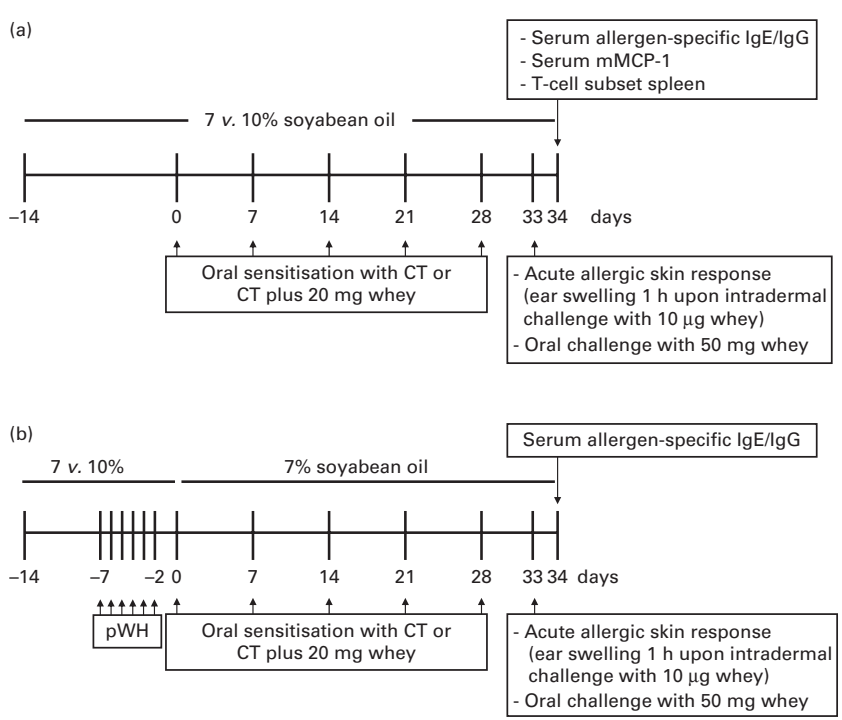

Fig. 1. Schematic overview of two different models used and parameters analysed in the present study. Protocols used for (a) oral sensitisation and (b) oral tolerance induction. CT, cholera toxin; mMCP-1, mouse mast cell protease-1; pWH, partial whey hydrolysate.

\section{Oral tolerance induction}

Whey was hydrolysed with an established mixture of endopeptidases and exopeptidases, according to a confidential enzyme composition used by Nutricia Research, resulting in pWH. The enzymatic process was stopped by fast cooling. pWH was characterised by the analysis of peptide size distribution $(85 \%<1 \mathrm{kDa}, 8 \%<2 \mathrm{kDa}, 4 \%<5 \mathrm{kDa}, 1 \%<10 \mathrm{kDa}, 0.6 \%$ $<20 \mathrm{kDa}$ and $1.4 \%>20 \mathrm{kDa}$ ) by means of HPLC. pWH has previously been shown to have limited sensitising properties, while retaining the ability to induce OT in mice ${ }^{(20,21)}$.

Before whey sensitisation, mice were fed the 7 or $10 \%$ soyabean oil diet from day -14 to 0 . In addition, from day -7 until day -2 , mice were daily treated intragastrically with $0.5 \mathrm{ml}$ PBS as a control or $50 \mathrm{mg} \mathrm{pWH} / 0.5 \mathrm{ml}$ PBS using a blunt needle (Fig. 1(b)), as described previously ${ }^{(21)}$. Subsequently, mice were sensitised and challenged, as described above, while being fed the $7 \%$ soyabean oil diet. At 1 week after the last sensitisation, the acute allergic skin response was measured upon intradermal whey challenge, and blood samples were collected the next day, after an oral challenge.

\section{Acute allergic skin response and anaphylaxis symptom score}

At $1 \mathrm{~h}$ after intradermal allergen challenge with $10 \mu \mathrm{g}$ whey in $20 \mu \mathrm{l}$ PBS in the pinnae of both ears, the acute allergic skin response was measured in duplicate for both ears using a digital micrometer (Mitutoyo). Isoflurane was used for inhalational anaesthesia during the measurements. Ear swelling was expressed as the difference $(\Delta, \mu \mathrm{m})$ in basal ear thickness before and $1 \mathrm{~h}$ after the intradermal whey challenge. To assess the severity of shock symptoms $30 \mathrm{~min}$ after the intradermal challenge, a validated anaphylaxis symptom scoring table was used $^{(22)}$. The system of scoring was as follows: 0, no symptoms; 1 , scratching nose and mouth; 2 , swelling around the eyes and 
mouth, piloerection, reduced activity, and higher breathing rate; 3 , shortness of breath, blue rash around the mouth and tail, and higher breathing rate; 4 , no activity after stimulation, shivering, and muscle contractions; 5 , death by shock.

\section{Serum levels of Ig, mouse mast cell protease-1 and $P G E_{2}$}

Whey-specific IgE and IgG1 levels were determined by ELISA in serum as described previously ${ }^{(18,23)}$. The serum concentrations of mouse mast cell protease-1 (mMCP-1) and $\mathrm{PGE}_{2}$ were determined using a commercially available ELISA kit (mMCP-1: Moredun Scientific Limited; $\mathrm{PGE}_{2}$ : Cayman Chemical), according to the manufacturer's protocol

\section{Erythrocyte fatty acid composition}

Blood samples were collected in heparin tubes, and plasma was removed after centrifugation. Erythrocytes were stored in $-70^{\circ} \mathrm{C}$ until analysis. Erythrocyte lipids were extracted as described by Bligh \& Dyer ${ }^{(24)}$, and membrane fatty acid composition was assessed using GC as described previously ${ }^{(25)}$.

\section{Passive sensitisation: transfer of hyperimmune serum to recipients}

To generate hyperimmune serum, each mouse was immunised intraperitoneally with $100 \mu \mathrm{l}$ whey (100 $\mu \mathrm{g})$ in PBS plus alum ( $2 \mathrm{mg}$ ) on days 0,7 and 21, after which blood was collected on day 28. Pooled ('hyperimmune') serum from mice immunised intraperitoneally with whey alum was intravenously transferred $(100 \mu \mathrm{l})$ to isoflurane-anaesthetised ( $5 \%$ in air) naive mice. The latter group (naive mice) were fed the 7 or $10 \%$ soyabean oil diet for 2 weeks before injection with hyperimmune serum ( $n 6$ mice per group). The acute skin response was measured $30 \mathrm{~min}$ after serum transfer, as described previously, starting with the measurement of ear thickness at basal conditions before the intradermal allergen challenge, followed by the assessment of ear swelling at $1 \mathrm{~h}$ after the intradermal challenge.

\section{Assessment of T-cell subsets by flow cytometry}

Single-cell splenocyte suspensions were obtained by passing the organs through a $70 \mu \mathrm{m}$ filter. The cells were blocked for $20 \mathrm{~min}$ in PBS containing $1 \%$ bovine serum albumin and $5 \%$ fetal calf serum. The suspended cells $\left(5 \times 10^{5} /\right.$ well $)$ were plated and incubated for $30 \mathrm{~min}$ at $4^{\circ} \mathrm{C}$ with different antibodies (eBioscience or $\mathrm{BD}$, unless otherwise stated) against CD4, CD69, CXCR3, T1ST2, CD25 (Miltenyi) and isotype controls. The cells were fixed using $0.5 \%$ paraformaldehyde and permeabilised for intracellular staining with anti-FoxP3 using the Foxp3 staining buffer set (eBioscience), according to the manufacturer's protocol. Flow cytometry was performed using FACS Canto II (BD) and analysed using FACSDiva software (BD).

\section{Statistical analyses}

Data are presented as means with their standard errors of the mean. Statistical analyses were performed using one-way or two-way ANOVA and post hoc Bonferroni test with GraphPad Prism software (version 5.0) or IBM SPSS statistics (version 20). For anaphylaxis symptom score data, the Kruskal-Wallis test was used followed by Dunn's multiple comparison test, and erythrocyte membrane PUFA content was analysed using Student's $t$ test. Where necessary, log transformation was used to normalise data distribution for analysis, followed by the use of Tukey's box-and-whisker plots. $P<0.05$ was considered as statistically significant.

\section{Results}

Increased dietary intake of soyabean oil enhances the acute allergic skin response

Allergic outcomes were studied in mice fed the $7 v .10 \%$ soyabean oil diet before and during oral sensitisation. Sensitisation with whey resulted in an enhanced acute allergic skin response upon intradermal whey challenge compared with sham-sensitised mice fed the 7 or $10 \%$ soyabean oil diet (Fig. 2(a)). Furthermore, the acute allergic skin response was significantly increased in whey-sensitised mice fed $10 \%$ soyabean oil compared with $7 \%$ soyabean oil. To study whether this difference in the acute allergic skin response was associated with alterations in the Th2-type humoral response, serum allergen-specific antibodies were measured. Both whey-specific IgE and IgG1 levels were enhanced in sensitised mice compared with sham-sensitised mice, but were not affected by increasing dietary soyabean oil content (Fig. 2(b) and (c), respectively). Food intake and body weight were equal in all groups during the experiment (data not shown).

\section{High-soyabean oil diet increases erythrocyte membrane linoleic acid content}

LA content in erythrocyte membranes was enhanced in wheysensitised mice fed 10\% soyabean oil compared with $7 \%$ soyabean oil, whereas other FA levels in the membrane were not significantly altered (Fig. 2(d)). The concentration of the AA-derived eicosanoid $\mathrm{PGE}_{2}$ did not differ between the groups fed 7 or $10 \%$ soyabean oil (Fig. 2(e)).

\section{High-soyabean oil diet enhances the allergic effector response}

To determine the effect of increased intake of $n$ - 6 PUFA-rich soyabean oil on mucosal mast cell degranulation, serum concentrations of mMCP-1 after oral challenge were measured in whey-sensitised mice. Serum mMCP-1 concentrations increased in the group fed $10 \%$ soyabean oil (Fig. 3(a)). To determine whether the local effector response was altered by increased soyabean oil intake, naive mice fed 7 or $10 \%$ soyabean oil were passively sensitised with whey hyperimmune serum and intradermally challenged with whey in the ear. Recipient mice in the $10 \%$ soyabean oil-fed group 

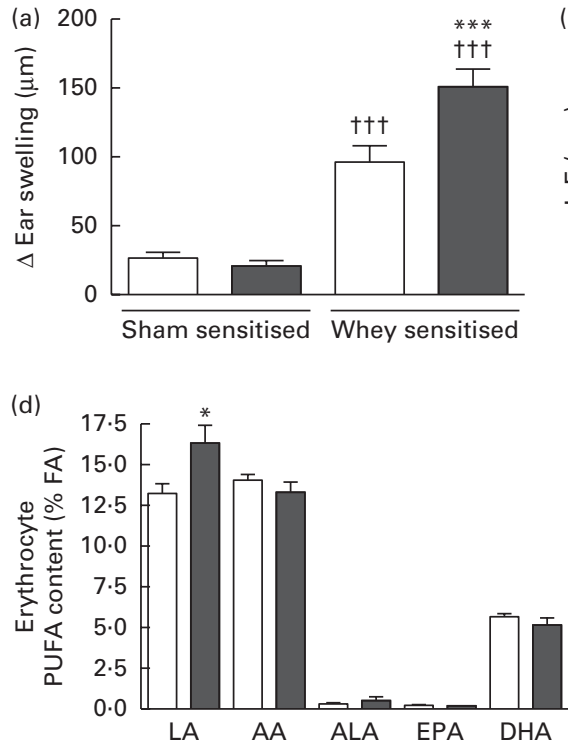
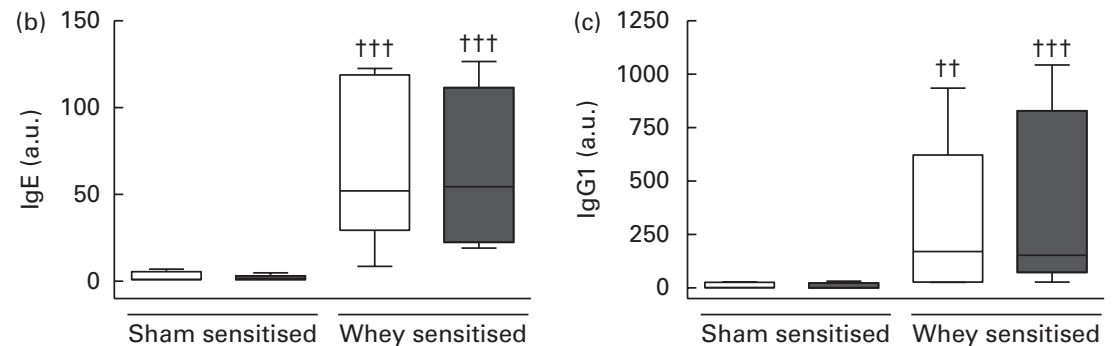

Fig. 2. Effects of a $7 \%(\square)$ v. $10 \%(\square)$ soyabean oil diet on the (a) acute allergic skin response assessed $1 \mathrm{~h}$ upon intradermal whey challenge (difference $(\Delta)$ in ear swelling), and whey-specific (b) IgE and (c) IgG1 levels in serum at $18 \mathrm{~h}$ after oral challenge. (d) Erythrocyte membrane fatty acid composition in whey-sensitised mice. (e) Serum PGE 2 . (a, d, e) Values are means ( $n 6$ mice per group), with their standard errors represented by vertical bars. (b, $c)$ Data are expressed as Tukey's box-and-whisker plots ( $n 6$ mice per group). Mean value was significantly different from that of the $7 \%$ soyabean oil diet within the group: * $P<0.05$ (Student's $t$ test), ${ }^{* \star \star} P<0.001$ (two-way ANOVA followed by Bonferroni's multiple comparison test). Mean value was significantly different from that of shamsensitised mice: $\dagger P<0.01$, $† \dagger \dagger P<0.001$ (two-way ANOVA followed by Bonferroni's multiple comparison test (after log transformation for lgE and IgG1)). a.u., Arbitrary units; FA, fatty acids; LA, linoleic acid; AA, arachidonic acid; ALA, $\alpha$-linolenic acid.

receiving hyperimmune serum exhibited a higher acute allergic skin response compared with the $7 \%$ soyabean oil-fed group (Fig. 3(b)). This confirms that in accordance with the mucosal mast cell response, the local effector response was also enhanced upon feeding the $10 \%$ soyabean oil diet.

\section{High-soyabean oil diet enhances the Th2:Th1 and Th2:regulatory $T$ cells ratios in sham-sensitised mice}

To determine the effect of a diet rich in $n-6$ PUFA during sensitisation on the adaptive immune system, T-cell subsets in the spleen were studied. In sham-sensitised mice fed $10 \%$ soyabean oil, the percentages of activated Th2 and Th1 cells were enhanced compared with mice fed $7 \%$ soyabean oil (Fig. 4(a)-(c)). As a result of a more pronounced increase in the percentage of Th2 cells compared with Th1 cells in sham-sensitised mice fed $10 \%$ soyabean oil, the Th2:Th1 ratio increased compared with sham-sensitised mice fed $7 \%$ soyabean oil, and remained high upon whey sensitisation (Fig. 4(e)). Whey-sensitised mice fed $7 \%$ soyabean oil exhibited an increase in the percentage of activated Th1 and Th2 cells and an enhanced Th2:Th1 ratio compared with shamsensitised mice fed $7 \%$ soyabean oil. Although the percentage of $\mathrm{CD} 25^{+} \mathrm{FoxP}^{+} \mathrm{T}$ cells within the $\mathrm{CD}^{+}$population was enhanced in sham-sensitised mice fed $10 \%$ soyabean oil (Fig. 4(d)), the Th2:CD25 ${ }^{+} \mathrm{FoxP}^{+}$Treg ratio was still
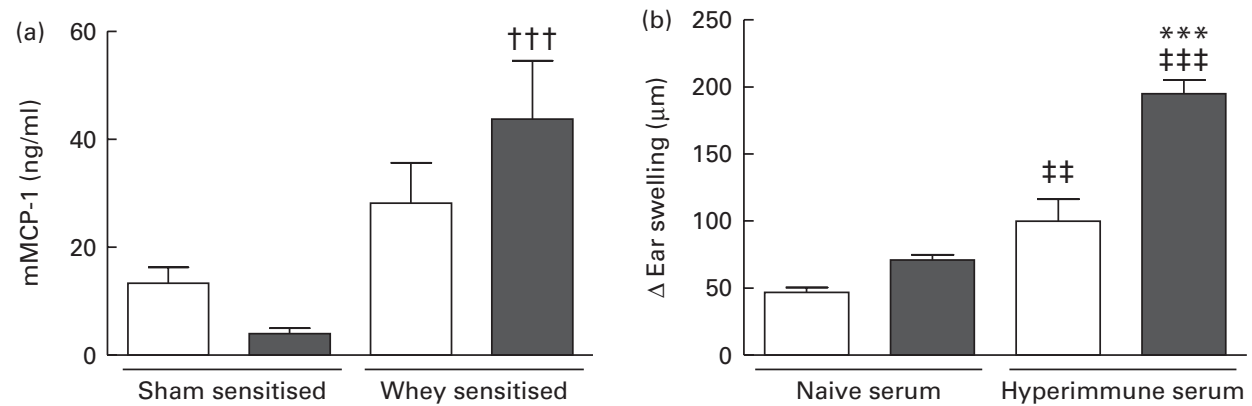

Fig. 3. Effects of dietary $n-6$ PUFA intake on the allergic effector response. (a) Serum concentration of mucosal mast cell protease-1 (mMCP-1) as a measure of mucosal mast cell degranulation. (b) Acute allergic skin response (difference $(\Delta)$ in ear swelling) was measured in naive recipient mice fed $7 \%$ ( $\square$ ) or $10 \%$ ( $\square$ ) soyabean oil before sensitisation with naive or whey hyperimmune serum and an intradermal whey challenge. Values are means ( $n 6$ mice per group), with their standard errors represented by vertical bars. ${ }^{\star * *}$ Mean value was significantly different from that of the $7 \%$ soyabean oil diet within the group $(P<0.001$; two-way ANOVA followed by Bonferroni's multiple comparison test). ††† Mean value was significantly different from that of sham-sensitised mice $(P<0.001$; two-way ANOVA followed by Bonferroni's multiple comparison test). Mean value was significantly different from that of naive mice: $\ddagger \ddagger P<0.01$, $¥ \ddagger \ddagger P<0.001$ (two-way ANOVA followed by Bonferroni's multiple comparison test). 
(a)
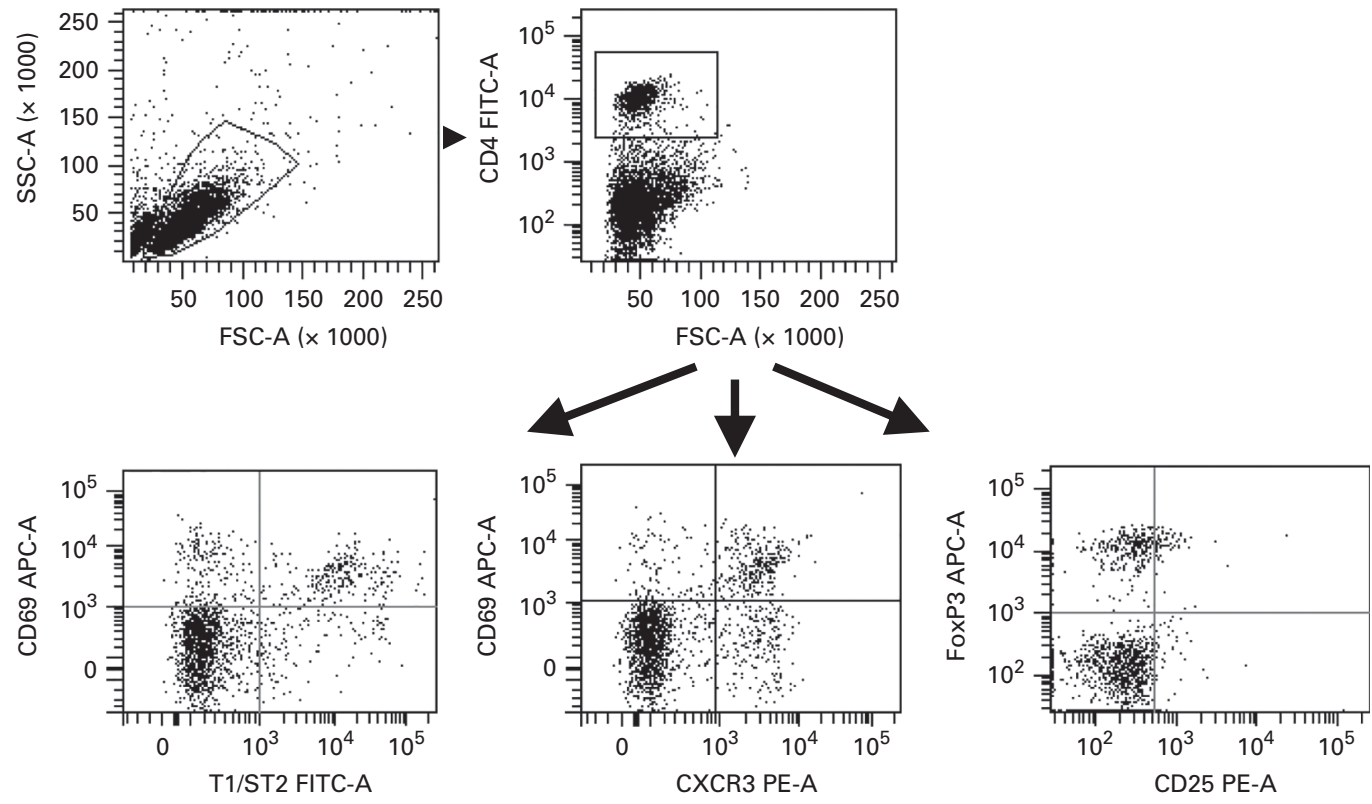

(b)
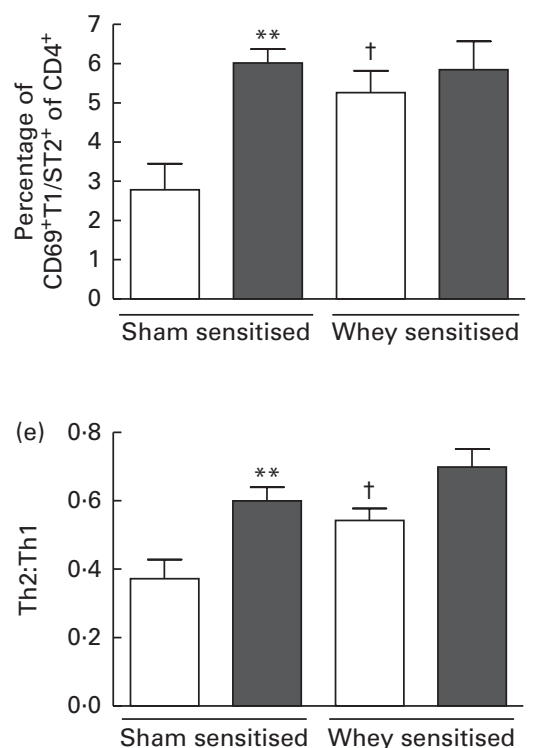

(c)
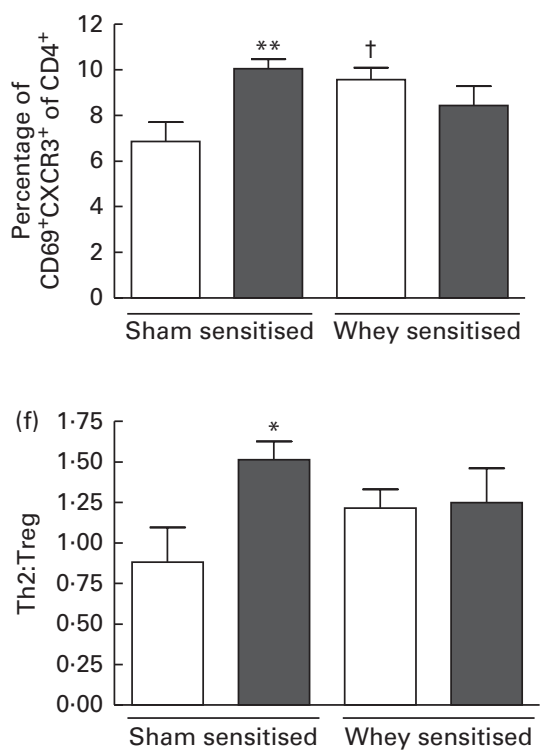

$(d)$

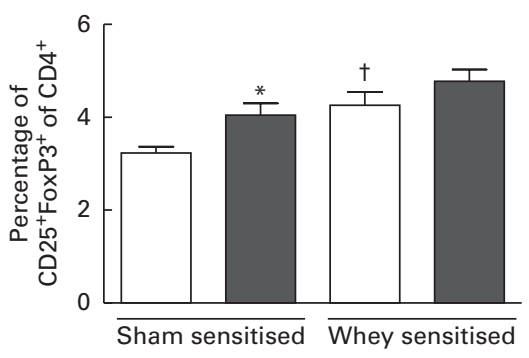

Fig. 4. Effects of oral allergen challenge on splenic T-cell subsets. (a) Representative dot plots of activated Th2 cell $\left(\mathrm{CD} 4^{+} \mathrm{CD} 69^{+} \mathrm{T} 1 / \mathrm{ST} 2^{+}\right)$analysis in the spleen Lymphocytes were gated based on the forward scatter-side scatter (FSC-SSC) pattern, followed by the analysis of the expression of CD4. Then, co-expression of CD69 and T1/ST2 (activated Th2 cells); CD69 and CXCR3 (activated Th1 cells), or CD25 and FoxP3 (regulatory T cells; Treg) was analysed. Percentages of activated (b) Th2 cells, (c) Th1 cells and (d) CD25 ${ }^{+} \mathrm{FoxP}^{+}{ }^{+}$Treg cells were determined. (e) Th2:Th1 ratio and (f) Th2:Treg ratio were also calculated. Values are means ( $n 6$ mice per group), with their standard errors represented by vertical bars. Mean value was significantly different from that of the $7 \%$ soyabean oil diet within the group: ${ }^{*} P<0.05,{ }^{* *} P<0.01$ (two-way ANOVA followed by Bonferroni's multiple comparison test). $†$ Mean value was significantly different from that of sham-sensitised mice $(P<0.05$; two-way ANOVA followed by Bonferroni's multiple comparison test). $\square, 7 \%$ Soyabean oil; $\square, 10 \%$ soyabean oil.

increased in the same group fed $10 \%$ soyabean oil compared with those fed $7 \%$ soyabean oil (Fig. 4(f)).

\section{Increased dietary intake of soyabean oil prevents oral tolerance induction by partial whey hydrolysate}

To study the effect of $7 v .10 \%$ soyabean oil on OT induction by $\mathrm{pWH}$, the different diets were fed for 2 weeks before sensitisation and $\mathrm{pWH}$ was given orally during the last $5 \mathrm{~d}$ prior to sensitisation (Fig. 1(b)). Subsequently, mice received the $7 \%$ soyabean oil diet during the sensitisation period. pWH partially induced OT to whey in mice fed $7 \%$ soyabean oil as the acute allergic skin response was reduced compared with non-tolerised mice (Fig. 5(a)). Tolerance induction by $\mathrm{pWH}$ was suppressed when mice were fed $10 \%$ soyabean oil during $\mathrm{pWH}$ treatment before whey sensitisation. Also, anaphylactic symptoms were significantly enhanced in mice fed $10 \%$ soyabean oil compared with $7 \%$ soyabean oil during pWH treatment (Fig. 5(b)). Whey-specific IgE levels were increased in whey-sensitised mice pre-fed with 7 and $10 \%$ 
(a)

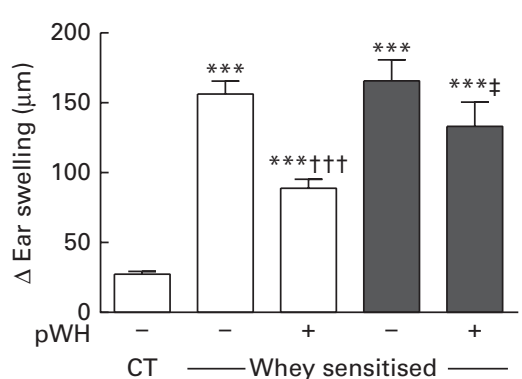

(b)

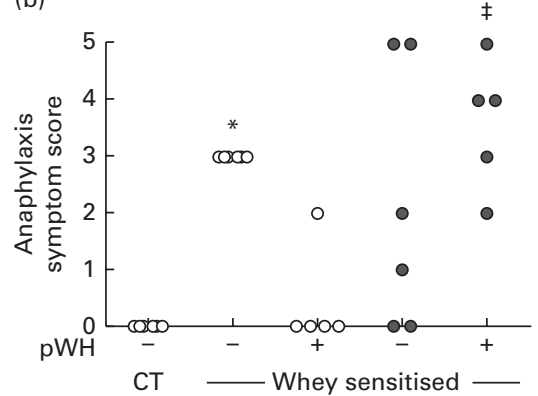

(c)

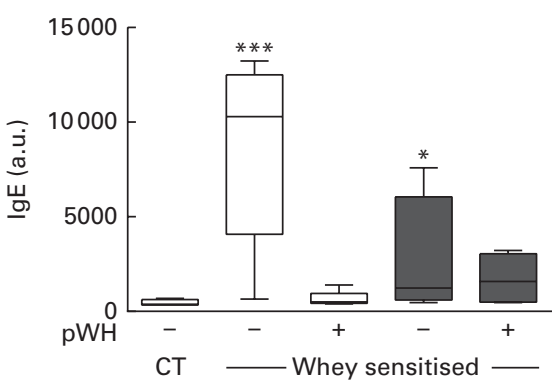

Fig. 5. Effects of increased soyabean oil intake on oral tolerance induction. In the oral tolerance model, mice were pretreated with a 7 or $10 \%$ soyabean oil diet in the presence or absence of partial whey hydrolysate $(\mathrm{pWH})$ followed by whey sensitisation while being fed the $7 \%$ soyabean oil diet. Assessment of (a) the acute allergic skin response evaluated $1 \mathrm{~h}$ upon intradermal challenge (difference $(\Delta)$ in ear swelling), (b) the anaphylaxis symptom score (scatter plot) and (c) wheyspecific lgE levels in serum at $18 \mathrm{~h}$ after oral challenge. (a) Values are means ( $n$ 4-6 mice per group), with their standard errors represented by vertical bars. (c) Data are expressed as Tukey's box-and-whisker plots ( $n$ 4-6 mice per group). Mean value was significantly different from that of cholera toxin (CT): ${ }^{*} P<0.05$, ${ }^{* * *} P<0.001$ (one-way ANOVA followed by Bonferroni's multiple comparison test (after log transformation for IgE) and Kruskal-Wallis test followed by Dunn's multiple comparison test (for anaphylaxis symptom score)). ††† Mean value was significantly different from that of the $7 \%$ soyabean oil diet in the absence of pWH $(P<0.001$; one-way ANOVA followed by Bonferroni's multiple comparison test). $¥$ Mean value was significantly different from that of the $7 \%$ soyabean oil diet in the presence of pWH $(P<0.001$; one-way ANOVA followed by Bonferroni's multiple comparison test and Kruskal-Wallis test followed by Dunn's multiple comparison test (for anaphylaxis symptom score)). a.u., Arbitrary units. $\square, 7 \%$ Soyabean oil (day -14 to 0 ); $\square, 10 \%$ soyabean oil (day -14 to 0 ); $\bigcirc, 7 \%$ soyabean oil (day -14 to 0 ); $\bullet, 10 \%$ soyabean oil (day -14 to 0 ).

soyabean oil. During pretreatment with pWH, whey-specific IgE levels were low in mice fed the $7 \%$ soyabean oil diet, while the levels tended to increase in mice fed the $10 \%$ soyabean oil diet compared with sham-sensitised mice $(P=0.077)$ (Fig. 5(c)).

\section{Discussion}

An increased intake of soyabean oil rich in $n-6$ PUFA enhances the severity of the allergic effector response in a murine model of cows' milk allergy, and prevents OT induction by $\mathrm{pWH}$.

A high dietary intake of $n-6$ PUFA may be a risk factor for the development of atopic disease. A high consumption of margarine (rich in LA) has been associated with an increased risk of asthma $^{(26-28)}$, allergic rhinitis ${ }^{(10,12,29,30)}$, eczema and allergic sensitisation $^{(9,10)}$. Consumption of margarine and vegetable oil in children has been linked to an enhanced risk of wheezing symptoms ${ }^{(31-33)}$, and consumption of more margarine and less butter and fish has been associated with the risk of atopic disease in children compared with non-atopic children ${ }^{(11)}$.

There are only a few studies addressing the effect of dietary fat percentage on allergic inflammation in the absence of obesity. High-fat diets used in rodent research typically contain up to $60 \%$ of energy from fat (commonly used to induce obesity quickly). Although the human diet naturally contains a higher percentage of fat (recommended daily intake of $30 \%$ of energy from fat), this proportion $(60 \%)$ would be considered extreme for a human diet. The semisynthetic rodent chow AIN93G ${ }^{(11)}$ contains $7 \%$ soyabean oil as a fat source. In the present study, we aimed to investigate the effect of a relatively moderate increase in dietary $n$ - 6 PUFA content on the development of cows' milk allergy. Increasing the content of soyabean oil from 7 to $10 \%$ did not induce an increase in body weight. Feeding young mice this diet represents a setting in which we study the effects of increasing doses of dietary $n-6$ PUFA on allergic outcomes early in life. We used this less extreme design to mimic the current Western-style diet that is rich in n-6 PUFA from vegetable oils (predominantly LA) such as soyabean oil.

When these diets were provided before and during oral sensitisation with whey, the acute allergic skin response was enhanced by the $10 \%$ soyabean oil diet. This effect was accompanied by enhanced serum concentrations of mMCP-1, reflecting enhanced mucosal mast cell degranulation ${ }^{(34)}$. Although the effector response was increased in whey-sensitised mice, no increase in the whey-specific IgE level could be detected. The acute allergic skin response was also enhanced in naive mice fed the $10 \%$ soyabean oil diet before passive immunisation. It indicates that increasing the amount of $n$ - 6 PUFA-rich soyabean oil in the diet enhances the allergic effector response independent of the humoral response. This may be attributed to an increased sensitivity of mast cells to degranulate, or altered mediator release by mast cells due to the increased consumption of dietary $n-6$ PUFA. Indeed, the $n-6$ PUFA AA, the main LA metabolite, dose-dependently increased IgE-mediated mast cell degranulation, as measured by the release of $\beta$-hexosaminidase in vitro. Furthermore, $\mathrm{PGD}_{2}$ secretion upon activation of mast cells was enhanced by AA incubation of mast cells ${ }^{(35)}$. This implies that the mast cell response may be altered by a diet rich in $n-6$ PUFA; consequently, the severity of allergic symptoms may increase. In diet-induced obese mice fed a diet containing 50\% soyabean oil and sensitised with ovalbumin, mast cell numbers were enhanced compared with non-obese control mice fed a $10 \%$ fat diet $^{(36)}$. Furthermore, increased dietary intake of soyabean oil may enhance reactivity to histamine in the skin. Indeed, it has been shown that vascular permeability increased in mice fed a $24 \%$ compared with $6 \%$ soyabean oil diet ${ }^{(37)}$, suggesting that a diet rich in $n-6$ PUFA may enhance allergic reactions. However, the limited increase in soyabean oil intake in the present study did not result in higher AA incorporation in erythrocyte membranes 
or an increase in the formation of the lipid mediator $\mathrm{PGE}_{2}$. By contrast, the LA content in erythrocyte membranes was enhanced in the $10 \%$ compared with $7 \%$ soyabean oil-fed mice. This may be of importance for the increase in allergic symptoms observed. Previously, an exchange of $6 \%$ of the $10 \%$ soyabean oil by EPA- or DHA-rich fish oil reduced allergic symptoms. This is likely to be the consequence of the increased content of erythrocyte membrane EPA and $\mathrm{DHA}^{(38)}$, and also reduced levels of LA were observed (data not shown). Fatty acids are known to alter NF- $\mathrm{BB}$ and mitogen-activated protein kinase pathways ${ }^{(7)}$, which may contribute to the effects observed. Indeed, free LA may have influenced these pathways or act via $G$ protein-coupled receptors, e.g. GPR $40^{(39)}$. However, to our knowledge, it is unknown whether mast cells express these receptors. Hence, the exact underlying mechanism by which the increase in soyabean oil intake enhances allergic symptoms is unknown, and needs to be further studied.

In the present study, the diet rich in $n-6$ PUFA enhanced the effector response, but did not affect the Th2-type humoral response, which is in accordance with the study of Yamaki et $a l .{ }^{(37)}$ showing that serum levels of IgE and IgG1 remained unaltered. By contrast, our previous results demonstrated that exchanging $6 \%$ of soyabean oil by fish oil rich in long-chain $n-3$ PUFA largely prevented the induction of the effector response and the allergen-specific antibody response in this murine model of whey sensitisation. Furthermore, fish oil also reduced the risk of allergic symptoms in mice orally sensitised with peanut extract ${ }^{(18,38)}$. Historically, the dietary ratio of $n$-6: $n$-3 PUFA approached 1:1; however, nowadays, in the Western diet, this ratio is 10:1 up to $25: 1$ because of a gradual decrease in $n-3$ PUFA consumption and excessive $n-6$ PUFA intake ${ }^{(40-42)}$. The higher ratio of $n-6: n-3$ PUFA in the diet may enhance the risk of asthma ${ }^{(43)}$. Furthermore, the risk of atopic disease and sensitisation has been associated with reduced $n$-3 PUFA levels and increased $n-6: n-3$ PUFA ratios in serum ${ }^{(44)}$. This indicates that the source of dietary fat is important in immune regulation. Indeed, the partial substitution of soyabean oil, rich in $n-6$ PUFA, by fish oil rich in long-chain $n-3$ PUFA largely prevented the risk of allergic sensitisation to whey in association with an enhanced frequency of FoxP3 ${ }^{+}$Treg cells and a reduced percentage of activated Th1 and Th2 cells ${ }^{(18)}$. This suggests that not the amount of fat per se but the fat source as such is important in the effects exerted in vivo. As allergic sensitisation occurs early in life or even in utero, maternal diet composition may also have consequences for the risk of developing allergic disease in newborns. Several studies supplementing pregnant women with fish oil have demonstrated a reduced risk of atopy in children at risk $^{(45-49)}$. By contrast, studies have demonstrated that high levels of total n-6 PUFA in breast milk are associated with an increased risk of atopic disease in children ${ }^{(50-52)}$. Furthermore, atopic children have higher LA and total PUFA levels resulting in a higher $n-6: n-3$ PUFA ratio in serum lipid fractions than healthy children ${ }^{(50)}$

Similar to the present study, Yamaki et al. ${ }^{(37)}$ showed that increased intake of dietary soyabean oil enhanced the Th2:Th1 ratio, which was demonstrated by increased Th2-type cytokine production and a trend towards decreased interferon- $\gamma$ levels in serum. Furthermore, Mizota et al. ${ }^{(53)}$ also demonstrated that the ratio of interferon- $\gamma$ :IL- 4 was reduced in culture supernatants of both mice and human subjects after being fed a $n-6$ PUFA-rich diet compared with a $n$ - 3 PUFA-rich diet, resulting in a shift towards an allergy-prone Th2 environment. In the present study, Th2 polarisation by a diet rich in $n$-6 PUFA was readily present in sham-sensitised mice, thus independent of allergic sensitisation. AA-derived eicosanoids such as $\mathrm{PGD}_{2}$ and other mediators such as histamine can induce dendritic cell activation and Th2 development ${ }^{(54,55)}$. Indeed, the enhanced Th2:Treg and Th2:Th1 ratio suggests Th2 skewing of the adaptive immune response by the $10 \%$ soyabean oil diet rich in $n-6$ PUFA. As a result, the susceptibility to develop allergic sensitisation instead of tolerance upon allergen exposure may increase. To determine whether increasing the dose of soyabean oil affects OT induction, mice were fed the different diets and treated with pWH before sensitisation. Hypoallergenic formulae containing partially hydrolysed peptides are often used to prevent allergies in children at risk. Previously, pWH has been demonstrated to be effective in inducing OT to whey in mice when fed a $7 \%$ soyabean oil diet ${ }^{(21)}$. However, combining $\mathrm{pWH}$ with the $10 \%$ soyabean oil pretreatment was shown to abrogate OT induction by $\mathrm{pWH}$. A study by van Esch et $a l .{ }^{(21)}$ demonstrated that $\mathrm{pWH}$ restored the frequency of Treg cells in the mesenteric lymph nodes (MLN) of wheysensitised mice to the same percentage found in shamsensitised mice. In the present study, the percentages of Treg, Th2/Treg and Th2/Th1 cells in MLN were not altered after sensitisation with whey nor by feeding the $10 \%$ soyabean oil diet (data not shown). It is unlikely that membrane fatty acids or NEFA obtained from the diet play a direct role in this experimental set-up since mice were fed the $7 \%$ fat diet during the sensitisation period. Therefore, we hypothesise that similar to the model where mice were fed the diets during sensitisation, Th2 polarisation occurs due to the highsoyabean oil diet in the period of OT induction before sensitisation. This may have resulted in a Th2-prone response to pWH instead of OT, leading to increased sensitivity to whey sensitisation. However, future studies are needed to further unravel the mechanism of suppression of tolerance induction by pWH using a $10 \%$ soyabean oil diet.

Increasing dietary intake of vegetable oil, rich in $n$-6 PUFA, enhances the severity of the allergic effector response and breaks OT induction in a murine model of cows' milk allergy. This suggests that dietary fat dose and source may have an impact on the susceptibility to develop allergic disease and severity of allergic symptoms.

\section{Acknowledgements}

The authors thank Martin Balvers for measuring fatty acid content in erythrocytes.

The present study was supported by a grant from the Nutricia Research Foundation. The Nutricia Research Foundation had no role in the design and analysis of the study or in the writing of this article. 
The authors' contributions are as follows: L. W. J. v. d. E. and L. E. M. W. designed the research with input from B. C. A. M. v. d. E. and J. G.; L. W. J. v. d. E., B. C. A. M. v. E., G. A. H. and G. M. D. conducted the research under the supervision of J. G. and L. E. M. W.; L. W. J. v. d. E. and L. E. M. W. analysed the data and wrote the manuscript. All authors read and approved the final manuscript.

The authors declare that they have no financial or personal conflicts of interest.

J. G. and Martin Balvers are employees of the Nutricia Research.

\section{References}

1. Black PN \& Sharpe S (1997) Dietary fat and asthma: is there a connection? Eur Respir J 10, 6-12.

2. Kankaanpaa P, Sutas Y, Salminen S, et al. (1999) Dietary fatty acids and allergy. Ann Med 31, 282-287.

3. Simopoulos AP (2011) Importance of the omega-6/omega-3 balance in health and disease: evolutionary aspects of diet. World Rev Nutr Diet 102, 10-21.

4. Burdge GC \& Calder PC (2005) Conversion of $\alpha$-linolenic acid to longer-chain polyunsaturated fatty acids in human adults. Reprod Nutr Dev 45, 581-597.

5. Stulnig TM (2003) Immunomodulation by polyunsaturated fatty acids: mechanisms and effects. Int Arch Allergy Immunol 132, 310-321.

6. Calder PC \& Miles EA (2000) Fatty acids and atopic disease. Pediatr Allergy Immunol 11, Suppl. 13, 29-36.

7. van den Elsen L, Garssen J \& Willemsen L (2012) Long chain $n-3$ polyunsaturated fatty acids in the prevention of allergic and cardiovascular disease. Curr Pharm Design 18, 2375-2392.

8. Pascual CY, Crespo JF, Perez PG, et al. (2000) Food allergy and intolerance in children and adolescents, an update. Eur J Clin Nutr 54, Suppl. 1, S75-S78.

9. Sausenthaler S, Kompauer I, Borte M, et al. (2006) Margarine and butter consumption, eczema and allergic sensitization in children. The LISA birth cohort study. Pediatr Allergy Immunol 17, 85-93.

10. Bolte G, Frye C, Hoelscher B, et al. (2001) Margarine consumption and allergy in children. Am J Respir Crit Care Med 163, 277-279.

11. Dunder T, Kuikka L, Turtinen J, et al. (2001) Diet, serum fatty acids, and atopic diseases in childhood. Allergy 56, 425-428.

12. von Mutius E, Weiland SK, Fritzsch C, et al. (1998) Increasing prevalence of hay fever and atopy among children in Leipzig, East Germany. Lancet 351, 862-866.

13. Venter C \& Arshad SH (2011) Epidemiology of food allergy. Pediatr Clin North Am 58, 327-349.

14. Rona RJ, Keil T, Summers C, et al. (2007) The prevalence of food allergy: a meta-analysis. J Allergy Clin Immunol 120, 638-646.

15. Burks AW, Laubach S \& Jones SM (2008) Oral tolerance, food allergy, and immunotherapy: implications for future treatment. J Allergy Clin Immunol 121, 1344-1350.

16. Malmberg LP, Saarinen KM, Pelkonen AS, et al. (2010) Cow's milk allergy as a predictor of bronchial hyperresponsiveness and airway inflammation at school age. Clin Exp Allergy 40, 1491-1497.

17. Reeves PG, Nielsen FH, Fahey GC, et al. (1993) AIN-93 purified diets for laboratory rodents: final report of the American Institute of Nutrition ad hoc writing committee on the reformulation of the AIN-76A rodent diet. J Nutr 123, 1939-1951.
18. van den Elsen LW, van Esch BC, Hofman GA, et al. (2013) Dietary long chain $n-3$ polyunsaturated fatty acids prevent allergic sensitization to cow's milk protein in mice. Clin Exp Allergy 43, 798-810.

19. Schouten B, van Esch BC, Hofman GA, et al. (2010) Oligosaccharide-induced whey-specific $\mathrm{CD} 25(+)$ regulatory $\mathrm{T}$-cells are involved in the suppression of cow milk allergy in mice. J Nutr 140, 835-841.

20. van Esch BC, Schouten B, Hofman GA, et al. (2010) Acute allergic skin response as a new tool to evaluate the allergenicity of whey hydrolysates in a mouse model of orally induced cow's milk allergy. Pediatr Allergy Immunol 21, 780-786.

21. van Esch BC, Schouten B, de Kivit S, et al. (2011) Oral tolerance induction by partially hydrolyzed whey protein in mice is associated with enhanced numbers of Foxp3 + regulatory T-cells in the mesenteric lymph nodes. Pediatr Allergy Immunol 22, 820-826.

22. Li XM, Schofield BH, Huang CK, et al. (1999) A murine model of IgE-mediated cow's milk hypersensitivity. J Allergy Clin Immunol 103, 206-214.

23. van Wijk F, Hoeks S, Nierkens S, et al. (2005) CTLA-4 signaling regulates the intensity of hypersensitivity responses to food antigens, but is not decisive in the induction of sensitization. I Immunol 174, 174-179.

24. Bligh EG \& Dyer WJ (1959) A rapid method of total lipid extraction and purification. Can J Biochem Physiol 37, 911-917.

25. Levant B, Ozias MK \& Carlson SE (2007) Diet (n-3) polyunsaturated fatty acid content and parity affect liver and erythrocyte phospholipid fatty acid composition in female rats. J Nutr 137, 2425-2430.

26. Nagel G \& Linseisen J (2005) Dietary intake of fatty acids, antioxidants and selected food groups and asthma in adults. Eur J Clin Nutr 59, 8-15.

27. Bolte G, Winkler G, Holscher B, et al. (2005) Margarine consumption, asthma, and allergy in young adults: results of the German National Health Survey 1998. Ann Epidemiol 15, 207-213.

28. Haby MM, Peat JK, Marks GB, et al. (2001) Asthma in preschool children: prevalence and risk factors. Thorax $\mathbf{5 6}$, 589-595.

29. Trak-Fellermeier MA, Brasche S, Winkler G, et al. (2004) Food and fatty acid intake and atopic disease in adults. Eur Respir J 23, 575-582.

30. Winkler G, Holtz H \& Doring A (1992) Comparison of food intakes of selected populations in former East and West Germany: results from the MONICA Projects Erfurt and Augsburg. Ann Nutr Metab 36, 219-234.

31. Foliaki S, Annesi-Maesano I, Tuuau-Potoi N, et al. (2008) Risk factors for symptoms of childhood asthma, allergic rhinoconjunctivitis and eczema in the Pacific: an ISAAC Phase III study. Int J Tuberc Lung Dis 12, 799-806.

32. Kim JL, Elfman L, Mi Y, et al. (2005) Current asthma and respiratory symptoms among pupils in relation to dietary factors and allergens in the school environment. Indoor Air 15, 170-182.

33. Farchi S, Forastiere F, Agabiti N, et al. (2003) Dietary factors associated with wheezing and allergic rhinitis in children. Eur Respir J 22, 772-780.

34. Schouten B, van Esch BC, Hofman GA, et al. (2008) Acute allergic skin reactions and intestinal contractility changes in mice orally sensitized against casein or whey. Int Arch Allergy Immunol 147, 125-134.

35. van den Elsen LW, Nusse Y, Balvers M, et al. (2012) n-3 Long-chain PUFA reduce allergy-related mediator release 
by human mast cells in vitro via inhibition of reactive oxygen species. Br J Nutr 109, 1821-1831.

36. Mito N, Kitada C, Hosoda T, et al. (2002) Effect of dietinduced obesity on ovalbumin-specific immune response in a murine asthma model. Metabolism 51, 1241-1246.

37. Yamaki K, Takano-Ishikawa Y, Goto M, et al. (2005) Effect of dietary fat on skin reactivity against histamine, Th1 and Th2 cytokine levels and some serum parameters in mice. Immunobiology 209, 703-709.

38. van den Elsen LW, Bol-Schoenmakers M, van Esch BC, et al. (2014) DHA-rich tuna oil effectively suppresses allergic symptoms in mice allergic to whey or peanut. J Nutr $\mathbf{1 4 4}$, 1970-1976.

39. Itoh Y, Kawamata Y, Harada M, et al. (2003) Free fatty acids regulate insulin secretion from pancreatic $\beta$ cells through GPR40. Nature 422, 173-176.

40. Leaf A \& Weber PC (1987) A new era for science in nutrition. Am J Clin Nutr 45, 1048-1053.

41. Simopoulos AP (1991) Omega-3 fatty acids in health and disease and in growth and development. Am J Clin Nutr 54, 438-463.

42. Simopoulos AP (2008) The importance of the omega-6/ omega-3 fatty acid ratio in cardiovascular disease and other chronic diseases. Exp Biol Med 233, 674-688.

43. Oddy WH, de Klerk NH, Kendall GE, et al. (2004) Ratio of omega-6 to omega-3 fatty acids and childhood asthma. J Asthma 41, 319-326.

44. Yu G, Kjellman NI \& Bjorksten B (1996) Phospholipid fatty acids in cord blood: family history and development of allergy. Acta Paediatr 85, 679-683.

45. Furuhjelm C, Warstedt K, Larsson J, et al. (2009) Fish oil supplementation in pregnancy and lactation may decrease the risk of infant allergy. Acta Paediatr 98, 1461-1467.

46. Furuhjelm C, Warstedt K, Fageras M, et al. (2011) Allergic disease in infants up to 2 years of age in relation to plasma omega-3 fatty acids and maternal fish oil supplementation in pregnancy and lactation. Pediatr Allergy Immunol 22, $505-514$.
47. Dunstan JA, Mori TA, Barden A, et al. (2003) Fish oil supplementation in pregnancy modifies neonatal allergen-specific immune responses and clinical outcomes in infants at high risk of atopy: a randomized, controlled trial. J Allergy Clin Immunol 112, 1178-1184.

48. Palmer DJ, Sullivan T, Gold MS, et al. (2012) Effect of $n$-3 long chain polyunsaturated fatty acid supplementation in pregnancy on infants' allergies in first year of life: randomised controlled trial. BMJ 344, e184.

49. Klemens CM, Berman DR \& Mozurkewich EL (2011) The effect of perinatal omega-3 fatty acid supplementation on inflammatory markers and allergic diseases: a systematic review. BJOG 118, 916-925.

50. Kankaanpaa P, Nurmela K, Erkkila A, et al. (2001) Polyunsaturated fatty acids in maternal diet, breast milk, and serum lipid fatty acids of infants in relation to atopy. Allergy 56, 633-638.

51. Soto-Ramirez N, Karmaus W, Zhang H, et al. (2012) Fatty acids in breast milk associated with asthma-like symptoms and atopy in infancy: a longitudinal study. J Asthma 49, 926-934

52. Wijga AH, van Houwelingen AC, Kerkhof M, et al. (2006) Breast milk fatty acids and allergic disease in preschool children: the Prevention and Incidence of Asthma and Mite Allergy birth cohort study. J Allergy Clin Immunol 117, 440-447.

53. Mizota T, Fujita-Kambara C, Matsuya N, et al. (2009) Effect of dietary fatty acid composition on Th1/Th2 polarization in lymphocytes. J Parenter Enteral Nutr 33, 390-396.

54. Theiner G, Gessner A \& Lutz MB (2006) The mast cell mediator PGD2 suppresses IL-12 release by dendritic cells leading to Th2 polarized immune responses in vivo. Immunobiology 211, 463-472.

55. Gosset P, Pichavant M, Faveeuw C, et al. (2005) Prostaglandin $\mathrm{D}_{2}$ affects the differentiation and functions of human dendritic cells: impact on the T cell response. Eur J Immunol 35, 1491-1500 